\title{
Медиасистема России и особенности ее развития
}

(Рецензия на учебное пособие: Медиасистема России /

под ред. Е.Л. Вартановой. М.: Аспект Пресс, 2020)

Наталия Урина

DOI: 10.30547/mediaalmanah.5.2020.142145

(c) Урина Наталия Валентиновна доктор филологических наук, старший научный сотрудник кафедры зарубежной журналистики и литературы факультета журналистики МГУ имени М.В. Ломоносова (г. Москва, Россия), natalia_urina@mail.ru
Интенсивное развитие медиа, их возрастающая роль и влияние на все сферы жизни актуализируют изучение этих процессов. Особого внимания заслуживают работы, посвященные национальным медиасистемам, их особенностям и перспективам развития. К таким работам, несомненно, можно отнести второе издание учебного пособия «Медиасистема России», подготовленное на факультете журналистики МГУ имени М.В. Ломоносова коллективом авторов под руководством и при участии профессора Е.Л. Вартановой. Это своевременное издание демонстрирует пример продуктивного и научно значимого подхода к разработке темы на новом, более высоком уровне, что касается всех аспектов исследования, включая теоретический.

Представляется весьма целесообразным наличие в первой главе обоснований принятого понятийного аппарата. Это относится прежде всего к понятиям «медиа» и «медиасистема». Справедливо акцентируется внимание на том, что медиа - это «многоаспектное понятие», имеющее несколько уровней (технологии, интегрированное социальное пространство и опосредованные медиатехнологиями коммуникационные процессы), т.е. явление. Аэто, в свою очередь, способствует восприятию медиасистемы как «особой... системы современных общественных институтов, тесно 
с ними связанной, а также как самостоятельной системы» (с. 9)1.

Далее при рассмотрении концепции национальной медиасистемы внимание акцентируется на тех факторах, которые определяют необходимость изучения структуры и особенностей функционирования медиасистемы России. К ним справедливо отнесены трансформация российской медиасистемы, демонстрирующая тесную связь структуры, природы и развития государства и национальных СМИ, затем уникальность в последние десятилетия «двойного перехода» от социалистической к рыночной экономике и демократии и от аналоговых СМИ к цифровым и, наконец, сложное сочетание влияний как национального, так и глобального характера.

При изучении такого сложного явления, как российская медиасистема, особую значимость приобретает выявление ее составляющих частей и роли каждой не только в отдельности, но и во взаимодействии между собой. В пособии предложена обоснованная сегментация системы с учетом различных факторов воздействия - от технологических до экономических. Такой подход позволяет анализировать очевидные и скрытые процессы развития сегментов, что дает возможность корректировать количество сегментов в системе и выявлять новые параметры их взаимодействия. Примером этого может служить введение нового сегмента «Социальные медиа», в результате чего их число возросло до 12:

- газеты;

- журналы;

- информационные агентства;

- радио;

- телевидение;

- интернет-СМИ;

- социальные медиа;

- книгоиздательские компании;

- киностудии, радио-и телепроизводящие компании;

- музыкальные звукозаписывающие студии;
- предприятия рекламного бизнеса;

- структуры системы связей с общественностью.

Для понимания современного состояния медиасистемы важно не только теоретическое, но и историческое знание, которому посвящена вторая глава пособия. В ней рассматриваются основные этапы развития отечественной медиасистемы, начиная со становления русской журналистики в XVIII в. и заканчивая советским периодом, что помогает высветить те факторы, которые в определенной мере определяют своеобразие системы в настоящее время.

Функционирование современной медиасистемы идет в правовом поле, ориентация в котором является обязательной для журналистов. В связи с этим резонно расширен и усовершенствован раздел, который посвящен вопросам правового и этического регулирования СМИ. В нем рассмотрена нормативно-правовая база в сфере СМИ и основные этапы ее развития, уделено внимание отношениям СМИ с гражданами и организациями, в том числе таким вопросам, как право на получение информации и право граждан на охрану частной жизни. Но особую значимость имеют темы, связанные с правами и обязанностями журналистов, а также этическим регулированием СМИ.

В пособии главы, посвященные теоретическим, историческим и правовым вопросам, формируют солидную основу, на которую затем накладываются разделы, связанные с анализом деятельности названных выше сегментов медиасистемы. Их анализ убедительно подтверждает то, что российские медиа проходят очередную стадию развития, которой присущи новые характерные черты.

Глава, посвященная сегменту печатных СМИ, насыщена большим количеством данных, в ней выявляются типологические особенности газетной и журнальной периодики, трансформация бумажных изданий, а также тенденции их развития. Следует 
отметить, что в оценке перспектив развития печати звучат и оптимистичные ноты. Они основаны на мнениях экспертов, которые считают, что «качество информации и достоверность ее источников является главным конкурентным преимуществом прессы», а потому «опыт печатной журналистики по подготовке качественного контента может оказаться весьма востребованным в будущем» (с. 128).

Далее в пособии рассматриваются информационные агентства как в историческом, так и в современном контексте, дается их типология, а также намечаются пути развития в новых технологических обстоятельствах. Последнее, как известно, еще в большей степени влияет на аудиовизуальные средства массовой информации, которым в пособии отведено значительное место. Так, сегмент радиовещания представлен в пособии в обновленном виде и обогатился за счет углубленного рассмотрения его системы. В ней выделены типы и форматы радиостанций и, что весьма важно, факторы влияния на радиовещание. Значительно усовершенствована глава, посвященная телевидению, в которой учтены новые веяния в его развитии. Российское телевидение представлено объемно, практически во всех возможных ракурсах: становление и факторы влияния на него, среди которых отмечены роль государства, территориальная структура, этнографическое разнообразие, принципы регулирования, реклама и медиаизмерители, а также три составляющие телесистемы (доставка телесигнала и телепрограмм на принимающие устройства, производство контента, организация и доставка контента телеканалами).

Принципиально важной является основательно обновленная глава, в которой речь идет об онлайн-СМИ. В ней отражены технологические предпосылки их формирования и их классификация. Вполне справедливо серьезное внимание уделено контенту онлайн-СМИ, особенностям потребления и аудитории, а также существующим бизнес-моделям. Следует отметить целесообразное рассмотрение перспектив развития онлайн-СМИ как полноценного и динамично развивающегося сегмента российской медиасистемы. Об этом, в частности, свидетельствует «главный тренд развития медиаиндустрии», связанный «со смещением фокуса деятельности всех без исключения компаний в онлайн-пространство и уходом "в цифру"» (с. 221). Возрастающая роль эксклюзивного контента способствует освоению новых методов и форм его распространения на различных площадках и формированию лояльной аудитории. В связи с этим множится потребление авторских видеоблогов, все четче проявляется ориентация на мобильных пользователей, реализуется применение искусственного интеллекта, внедряется автоматизированная генерация контента и возрастает популярность стримингов и подкастов. И, наконец, как отмечается в конце главы, начавшиеся эксперименты с виртуальной реальностью откроют в будущем новые возможности для медиаиндустрии.

Логичным продолжением анализа сегмента онлайн-СМИ является рассмотрение социальных медиа, которые выделены в самостоятельный сегмент. На фоне общей характеристики социальных медиа определяется обоснованность термина «социальные медиа», типы и группы социальных медиа, объединенные общими признаками. Важно, что в пособии пространно представлены особенности развития Рунета, включая функционирование социальных сетей, поисковых систем и мессенджеров, а также влияние блогеров, инфлюенсеров и «новых профессионалов». Тщательный анализ теоретического и эмпирического материала позволил авторам придти к выводу о том, что сделать точный прогноз направления и скорости развития социальных медиа весьма сложно, поскольку «это наиболее динамичная часть российской медиасистемы, которая активнее других отзывается 
на запрос аудитории, бизнеса, общества в целом» (с. 249).

О динамичности процессов, идущих в медиасистеме, свидетельствуют также сегменты киноиндустрии и книгоиздания. В данных сегментах не только выявляются их особенности и перспективы развития в России, но и устанавливается их место в современной медиасистеме, что напрямую связано с проблемами как технологического, так и экономического характера. Киноиндустрия, например, вынуждена выстраивать новые рекламные линии в связи с оттоком рекламы кинопрооектов с телевидения в Интернет и т.д.

Следует отметить, что экономическая составляющая присутствуетв описании всех сегментов медиасистемы. Но углубленно финансово-экономические вопросы отражены в главах «Реклама» и «Медиакомпании». В первой выстраивается развитие медиарекламного рынка в России, определяется значение рекламы в бизнес-модели, особенности рекламных продаж в СМИ и роль рекламы в медиаконтенте. Во второй прослеживается экономическая история медиасистемы России и предложена ее периодизация (1992-1998 гг., 1999-2008 гг., с 2009 г. по н.в.). Кроме того, обстоятельно сформулированы особенности российских медиахолдингов и процесса концентрации медийного капитала.

Нельзя не сказать об актуальности главы, посвященной связям с общественностью, в которой определены этапы развития и современные тенденции этого сегмента медиасистемы, охарактеризованы действующие типы коммуникаций и институциональная структура PR-рынка, а также профессиональное сообщество в сфере связей с общественностью. В завершающей главе, рассматриваются чрезвычайно важные и в то же время сложные вопросы, относящиеся к аудитории СМИ. В нее включены количественные и качественные характеристики аудитории, сформулированы проблемы медиапотребления и последовательно представлены аудитории телевидения, радио, печати и Интернета.

В целом, необходимо отметить компактную форму изложения материала и тщательно отобранные статистические данные и инфографику, соответствующие жанру учебного пособия. Полезным дополнением являются также Приложения, в которых содержится информация, связанная с законодательством и сферой саморегулирования СМИ, с крупнейшими медиахолдингами России и основными датами в истории российской журналистики. Новое издание пособия отчетливо демонстрирует не только то, как развивается российская медиасистема, обладающая рядом особенностей, но ито, как растетуровень ее исследований, продемонстрированный авторами. Это обстоятельство вселяет уверенность в то, что широкая аудитория, включая студентов и преподавателей, и в дальнейшем будет оснащена необходимой научной базой для изучения медиакоммуникации.

\section{Примечания}

1 Здесь и далее книга «Медиасистема России» цитируется с указанием страницы в круглых скобках. 